\title{
Monitoring of Ecosystem Dynamics in the Mojave Desert: the Beatley Permanent Plots
}

\section{Introduction}

Agencies responsible for land management in the Mojave Desert have a need to understand ecosystem dynamics, particularly the recovery that follows severe disturbances. Two major elements of the Recoverability and Vulnerability of Desert Ecosystems Program involve study of perennial vegetation recovery following severe disturbances and ecosystem changes in response to climatic fluctuations. Because its security controls disturbances, the Nevada Test Site (NTS) is an ideal place to conduct long-term ecosystem research.

Dr. Janice C. Beatley (fig. 1) was a researcher with the University of California, Laboratory of Nuclear Medicine and Radiation Biology. She contracted with the Atomic Energy Commission to do ecological work on NTS between the late1950s and the mid-1970s. In 1962, she established a network of 68 permanent ecological plots on NTS with the intent of addressing a number of long-term ecological questions. The plots are within the major vegetation assemblages of the Mojave Desert (fig. 2), and their siting was due in part to her interest in describing and mapping plant communities on NTS (Beatley, 1976).

Beatley published some of her data between the mid-1960s and early 1980s (Beatley, 1969, 1979, 1980), but most of the data she collected is unpublished. In addition, her plots were designed for repeated measurements and are ideal for assessing long-term change. After Dr. Beatley died in November 1987, her original data files, computer tapes, and printouts were transferred to the U.S. Geological Survey.

Reoccupation of the Beatley ecological study plots provides invaluable data on long-term changes in undisturbed Mojave Desert ecosystems. In addition, Beatley's study design allows an opportunity for assessing long-term recovery from several types of disturbances. This Fact Sheet gives a description of the Beatley permanent plots and their usefulness for addressing several important ecological questions.

\section{Types of Data Collected}

Beatley established 68 study plots in 1962 with the primary objective of documenting the effects of ionizing radiation from atmospheric nuclear explosions on typical Mojave Desert plant assemblages. With the moratorium on atmospheric testing in the fall of 1963, the plots attained a new set of objectives, mostly involving ecological questions concerning long-term change. The
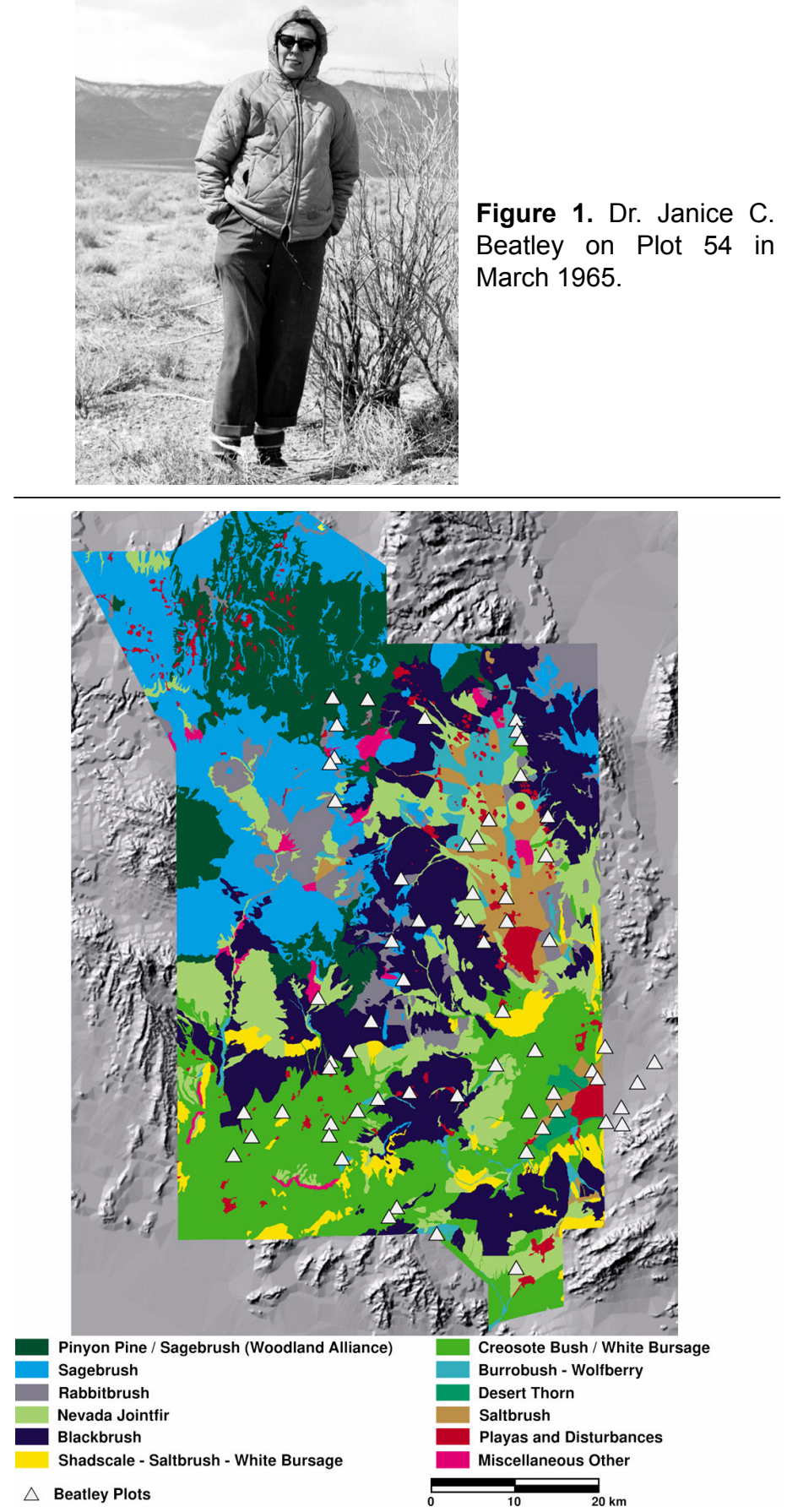

Figure 2. Vegetation distributions on the Nevada Test Site (Ostler and Hansen, 2000) in relation to the locations of the 68 Beatley ecological study plots. 


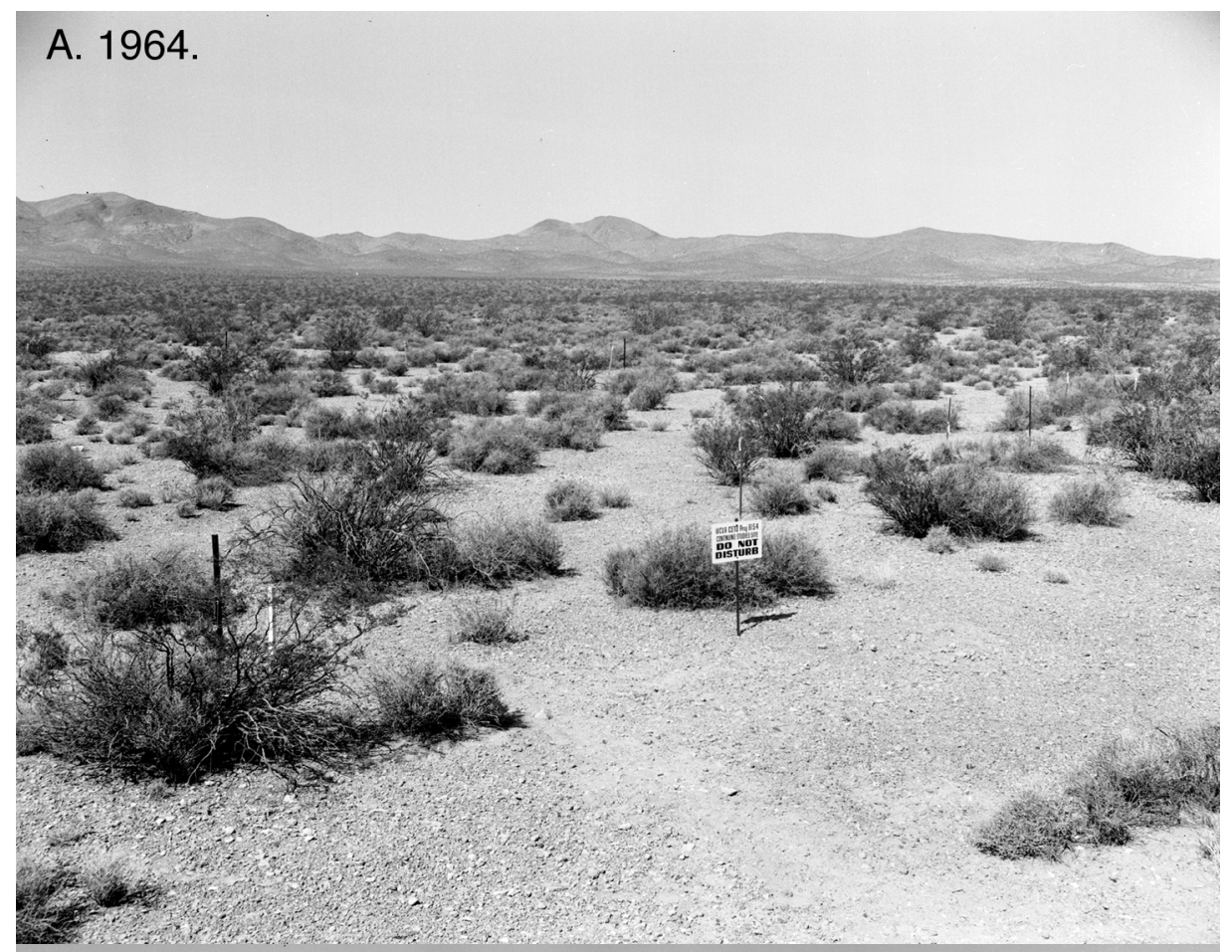

B. 2000.

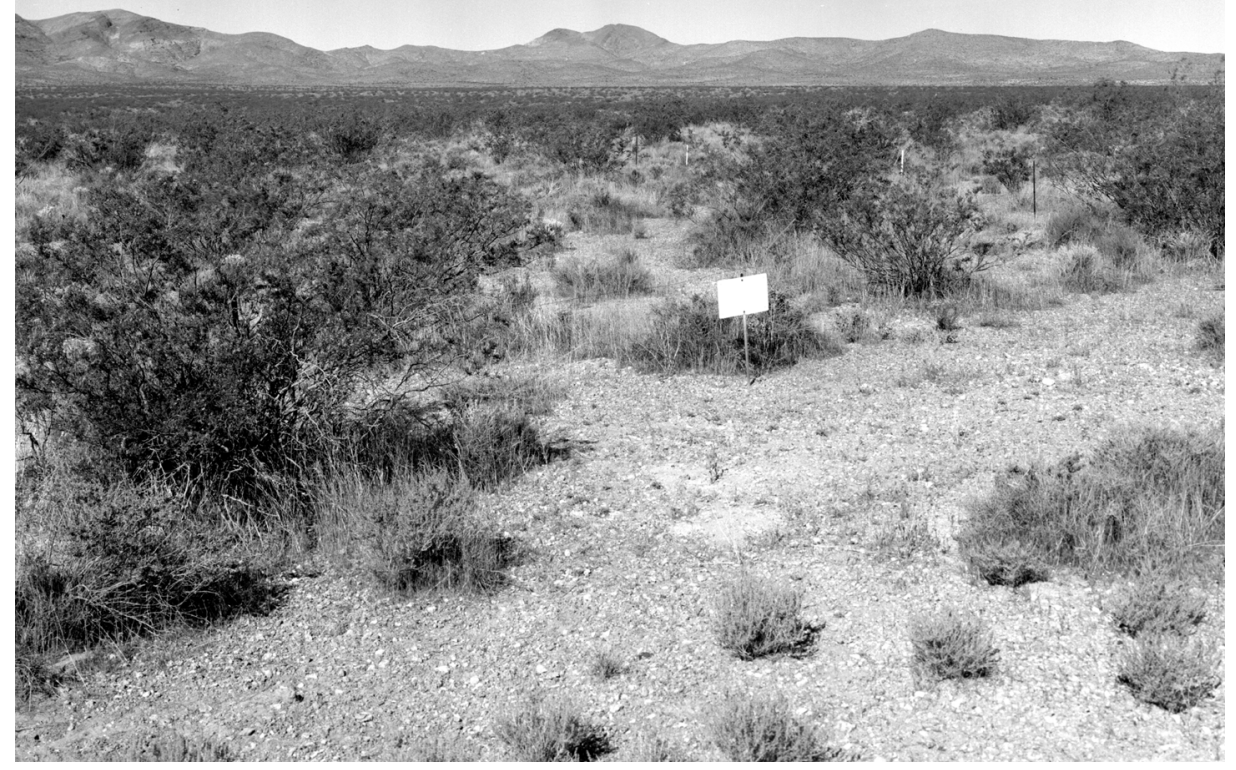

Figure 4. Plot 2 in a Larrea-Grayia-Lycium association. A. May 14, 1964. B. May 12, 2000. Most of the shrubs are still alive and much larger after 36 years.

plots are typical of the elevation and precipitation of the Mojave Desert (fig. 3).

Of the 68 plots, 59 plots are in undisturbed settings selected to document longterm ecological changes in "climax" vegetation (Beatley, 1980). Nine plots were established to document disturbance response; some of the disturbed plots were paired to nearby undisturbed plots. Several plots $(48,52-54)$ are sited to

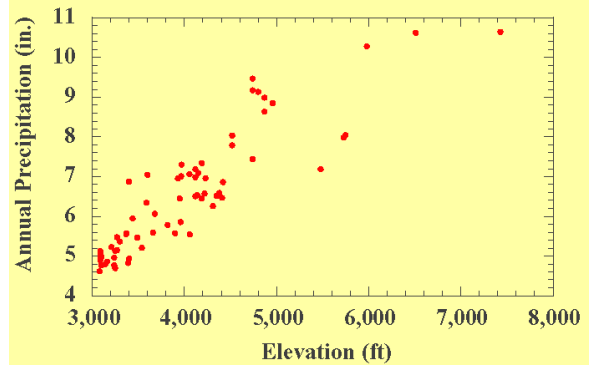

Figure 3. The 68 permanent ecological study plots depicted over their range of elevation and mean annual precipitation.

another (64) was damaged by road construction after 1975, another (57) was destroyed by construction and a new plot was established nearby in 1966, and three $(9,29$, and 31) were either damaged by gophers between 1963 and 1975 or had "questionable history" (Beatley, 1980).

Each plot was established with a primary goal of measurement of perennial vegetation within a 100 foot by 100 foot central area. At least three plots varied in dimensions from this overall design owing to site-specific objectives or geometric constraints. A perimeter fence cordoned off this area from vehicular use and extraneous trampling, and a sign stating the project name faced the nearest access point. A total of 67 plots were photographed from the bed of a truck in April and May, 1964, using a Crown Graphlex 4x5 view camera with a $135 \mathrm{~mm}$ lens. Replication of these photographs provides considerable data concerning long-term changes to the plots (fig. 4).

Rainfall, soil moisture, and maximum-minimum temperatures were measured for all plots at roughly two-week intervals between 1963 and 1975. Rainfall was measured in storage gages; the data is valuable for monthly and annual precipitation estimates only (fig. 3). Soil moisture was measured using gypsum blocks buried at 3, 6, and 9 in. depth. Maximumminimum temperatures were measured about 12 in. from the ground surface using recording mercury thermometers.

Woody perennial vegetation was measured in the central area using the lineintercept method on 100-foot lines spaced 10 feet apart and marked with large nails, hooked stakes, or wooden stakes at both ends of the transects. The intercept start and end were measured for each plant; and overlapping canopies were recorded separately, making the sum of the individ- 
ual plant covers greater than the total ground cover. Heights of individual plants and their phenological status were noted (Beatley, 1980). Perennial vegetation was measured in the summer and fall of 1963 and the spring of 1975. Herbaceous perennials - grasses and other nonwoody species - were measured annually between 1963 and 1967 and again in 1975 using the same methods used to measure woody perennials. An example

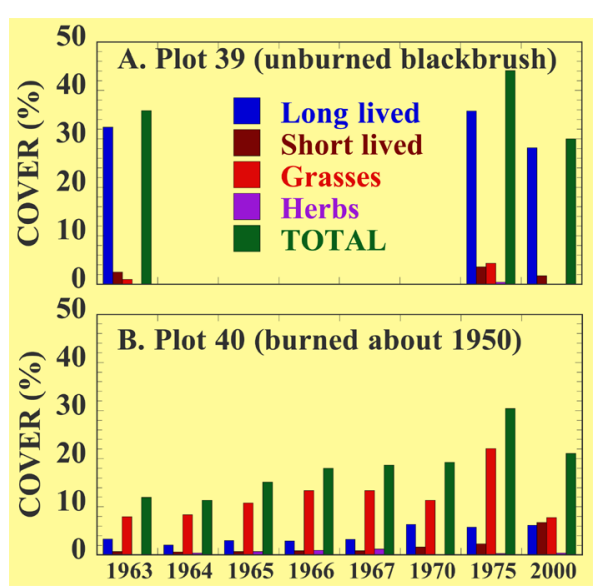

Figure 5. Perennial shrub cover on two permanent ecological plots on the Nevada Test Site. These graphs show recovery of blackbrush vegetation following a fire.

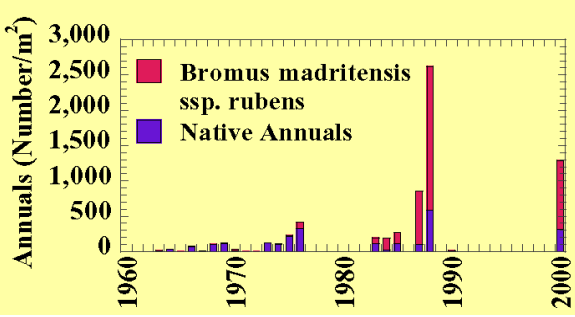

Figure 6. Time series of density of annual plants on the Nevada Test Site (averaged over all plots; Hunter, 1991). The data for 2000 are from plots 18-19, 39-42.

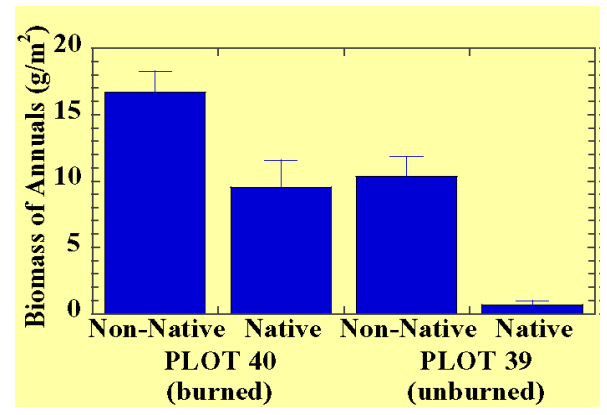

Figure 7. Comparison of native and nonnative annuals on plots 18-19, 39-40, and 41-42, which are paired burned-unburned plots, at least 41 years after a fire. of the combined woody and herbaceous perennial data appears in figure 5. This data, collected from Plots 39 and 40, illustrates recovery of perennial vegetation over a 50-year period following a fire.

Winter annuals were measured during their reproductive peak in April-May from 1964-1968 for 61 plots and 1964-1972 for plots 3, 4, 48, and 52-55. Cover-class estimates were made in quadrat frames placed along a line 10 feet outside of the central area and parallel to one of the sides (fig. 5). Each line was 100-ft long, and the $0.1 \mathrm{~m}^{2}$ frames were placed every 2 feet for a total of 50 estimates per plot (Beatley, 1969). Biomass of winter annuals was measured destructively at all 68 plots between 1964 and 1968 (Beatley, 1969). The side of the plot chosen varied to minimize cumulative-disturbance effects in subsequent years.

Small mammal transect lines were superimposed over the central area to form an effective trapping area of 1.14 ha. Seven lines with 7 traps - making a total of 49 trap stations - spaced at 15-m intervals formed the $91 \times 91 \mathrm{~m}$ grid. Each plot was sampled after the end of the reproductive season in July-September using Sherman live traps baited with rolled barley. Sampling occurred for 2 consecutive nights; this sampling protocol of only 2 nights per year precludes any assessment of absolute density of all rodents, but instead yields species composition information primarily on animals that are nocturnally active in July.

\section{Climatically Driven Changes}

Beatley (1980) concluded that most of the living plants in 1963 were still present when she remeasured her plots in 1975. An additional $20-30 \%$ of the plants measured in 1975 were new, and total cover had increased as a result of high rainfall in the late 1960s. Beatley concluded that the size and cover of woody perennial plants in the Mojave Desert are strongly correlated with precipitation.

The period between 1975, when Beatley last measured the plots, and 2000 had several climatic extremes. The period of 1977-1984 was one of the wettest periods of the 20th century, and extreme droughts occurred in 1989-1991 (Hunter, 1994), 1996, and 1999. Many shrubs died during these years, making droughts a major mechanism for change in Mojave Desert ecosystems. Despite the droughts, the increase in biomass between 1963 and 2000 is striking (fig. 4). Associations dominated by creosote bush (Larrea tridentata) had large increases in the sizes of individual plants as well as increases in total cover. Some blackbrush assemblages, in contrast, lost total cover (fig. 4), probably as a result of the droughts.

\section{Disturbance Recovery}

Part of Beatley's experimental design for plot location emphasized recovery from disturbance. As part of this study, she placed 3 sets of paired permanent vegetation plots in blackbrush stands in Topopah and Mid Valleys. Two of these plots were placed within a larger area that burned after a lightning strike in 1959, and the third was in an area that burned about 1950 .

Repeat photography shows several important changes in 36 years (fig. 8). First, Joshua trees (Yucca brevifolia) have increased dramatically in the background unburned areas. Mortality is so high, and growth rates are so large, that identifying common individuals between the two views is difficult. Our repeat photography supports the new view of Joshua trees as a relatively fast-growing and medium-lived species. In the burned plot, the cover and biomass of perennial vegetation - particularly woody shrubs - is obviously much higher after 36 years of recovery, indicating that recovery is occurring relatively quickly (fig. 5).

Although non-native brome grasses have been present on the plot since the 1960s (fig. 6), there is no indication at these sites that the vegetation will be converted to an annual grassland. The proportion of non-native to native annuals is higher on unburned plots (fig. 7), suggesting that disturbance alone does not always favor non-natives. However, this is a oneyear snapshot and there is no on-going disturbance at these sites.

Reoccupation of the permanent plot verifies what is visibly obvious in the photographs. One important caveat about the disturbance monitoring plots is that they are always paired by straddling them at the formerly "hard edge" of disturbances. This emphasizes recovery at disturbance edges adjacent to intact 
vegetation stands. We have considered recovery on the plots and made observations in the larger study area. One important insight is that there may have been as few as one blackbrush establishment event on burned sites during the past 3650 years. The pattern of germination also seems to be in a thin band along the edge of the disturbance, and no more than $10 \mathrm{~m}$ from the edge of the intact blackbrush stand. We hypothesize that this line may be linked to granivore activities.

Also of note is that blackbrush establishment seems to be rare in the intact stand. The amount of long-lived and short-lived shrubs in the plot has increased substantially since 1963 , as they have on undisturbed plots due to a recent (20 year) wet period. Blackbrush seedlings are now common on the plot, and several young Joshua trees were encountered in the plant transects.

In the 1960s and 1970s, grasses (notably Stipa speciosa) dominated the perennial vegetation on the plot. A drought in 1989 , one of the most severe in the history of southern Nevada, greatly reduced the grasses on the plot, and now the proportions of long-lived and short-lived shrubs are about equal to grasses in terms of vegetation cover (fig. 5B). Total cover on the burned plot is approaching the total cover on nearby undisturbed plots after 50 years of recovery, in accord with what is known of recovery in other types of disturbed areas even in more mesic climates. Despite the increases in woody vegetation, the species composition is not even close to the undisturbed plots, and extrap- olation suggests that as long as a millennium will be required for recovery of species composition.

\section{Benefits of Long-Term Monitoring}

The Beatley permanent plots represent long-term monitoring that is beneficial to researchers and land managers. They provide critical ecological information that can be collected in no other way. This Fact Sheet illustrates opportunities to generate and test hypotheses about environmental change far outside the normal time-frame of 3-5 year funding cycles. From these plots, we are generating information about disturbance-recovery regimes, climate change, non-native plant invasions, and plant/animal interactions through synthesis of data collected over a half century. What we learn from the Beatley plots is stimulating discovery and insight for a geographic area much greater than that occupied by the sites, and of immediate use to managers, researchers, and the general public. These plots are also generating significant ecological hypotheses that will be tested using fieldscale experiments.

We wish to thank the U.S. Department of Energy, Nevada Operations Office, and Bechtel Nevada for their logistical and technical support.

\section{-Robert H. Webb, Todd C. Esque, Philip A. Medica, Lesley A. DeFalco, and} Marilyn B. Murov

\section{Selected References}

Beatley, J.C., 1969, Biomass of desert winter annual plant populations in southern Nevada: Oikos, v. 20, p. 261-273.

Beatley, J.C., 1976, Vascular plants of the Nevada Test Site and central-southern Nevada: Springfield, VA, National Technical Information Service, TID-26881, 308 p

Beatley, J.C., 1979, Shrub and tree data for plant associations across the Mojave/Great Basin desert transition of the Nevada Test Site, 1963-1975: Springfield, VA, National Technical Information Service, DOE/EV/ 2307-15 U-48, $52 \mathrm{p}$.

Beatley, J.C., 1980, Fluctuations and stability in climax shrub and woodland vegetation of the Mojave, Great Basin and Transition Deserts of southern Nevada: Israel Journal of Botany, v. 28, p. 149-168.

Hunter, R.B.,1991, Bromus invasions on the Nevada Test Site: present status of $B$. rubens and $B$. tectorum with notes on their relationship to disturbance and altitude: Great Basin Naturalist, v. 51, p. 176-182.

Hunter, R.B., 1994, Status of the flora and fauna on the Nevada Test Site, 1989-1991: Las Vegas, U.S. Department of Energy, Nevada Operations Office, Report DOE/ NV/11432-57,

Ostler, W.K., Hansen, D.J., Anderson, D.C., and Hall, D.B., 2000, Classification of Vegetation on the Nevada Test Site: Las Vegas, Department of Energy, Nevada Operations Office, Report DOE/NV/11718-477.

For more information, contact: Robert $\mathrm{H}$. Webb, U.S. Geological Survey, 1675 W. Anklam Road, Tucson, AZ 85745; email: rhwebb@usgs.gov
A. 1964.
B. 2000.
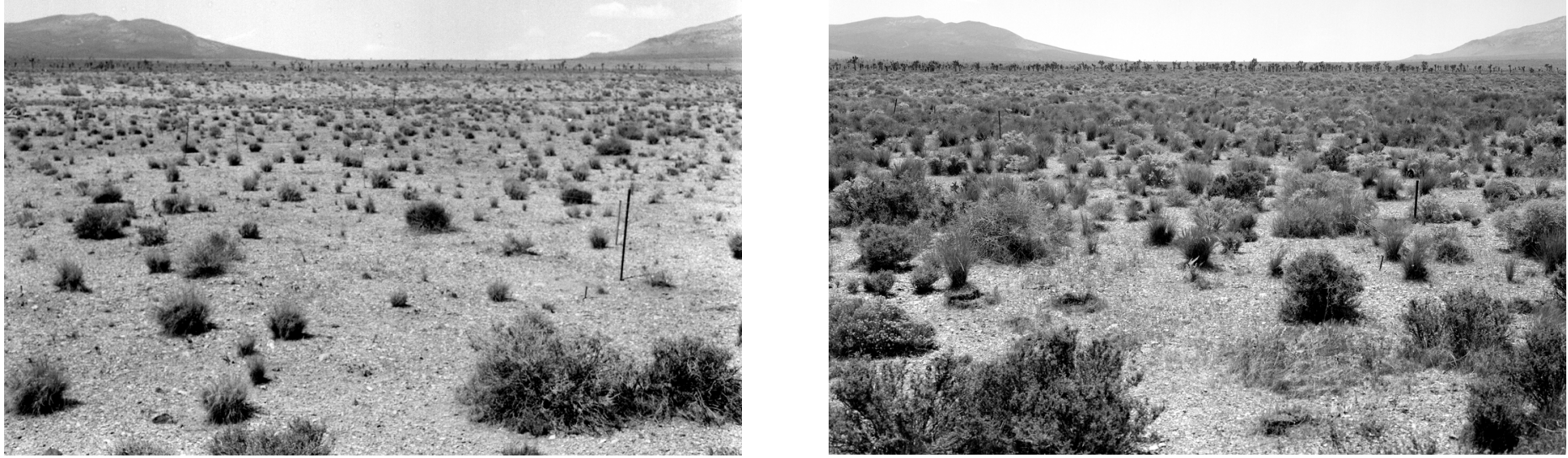

Figure 8. Repeat photography of plot 40, Nevada Test Site, showing recovery in a formerly blackbrush (Coleogyne ramosissima) assemblage following a fire in about 1950. A. May 1964. B. May 10, 2000. Note the density of Joshua tree (Yucca brevifolia) increased substantially from 1964 to 2000 in the unburned area in the background. Most of the shrubs are Mormon tea (Ephedra nevadensis). 